\title{
Multinanosensors Based on MWCNTs and Biopolymer Matrix - Production and Characterization
}

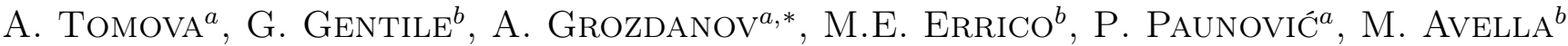 \\ AND A.T. Dimitrov ${ }^{a}$ \\ ${ }^{a}$ Faculty of Technology and Metallurgy, Sts. Cyril and Methodius, Skopje, Macedonia \\ ${ }^{b}$ Institute for Polymers, Composites and Biomaterials, National Research Council, \\ via Campi Flegrei 34, 80078 Pozzuoli, Napoli, Italy \\ (Received 25 July, 2016; in final form 30 November, 2016)
}

\begin{abstract}
This study presents the results of the design and characterization of a gas sensor with PMMA/CNTs chemiresistor as sensing element for detection of organic vapors. Multi wall carbon nanotubes (MWCNTs) produced at our lab (by method of pyrolysis, outer diameter $d=10 \div 40 \mathrm{~nm}$, purity $\approx 94 \%$ ) were incorporated into biocompatible polymer matrix. Poly(methyl methacrylate) - PMMA - and nanocomposite films were obtained using casting solution technique. Produced nanocomposite films were investigated with thermogravimetric analysis, differential scanning calorimetry, X-ray analysis, scanning electron microscopy, and Fourier transform infrared, while the sensors activity was determined by the changes in electrical resistance of the nanocomposite films due to acetone and chloroform exposure. The response to these vapors was evaluated and it was shown that PMMA/MWCNTs composites exhibit changes in electroresistivity. Sensitivity was calculated to be in $0.58-54.6$ range (30 min exposed to acetone) and $0.53-10.35$ (30 min exposed to chloroform). The results presented in this paper show that CNTs are able to improve the overall performances of polymer based sensors.
\end{abstract}

DOI: 10.12693/APhysPolA.132.1251

PACS/topics: sensors, actuators, composites, nanotubes, properties and characterization

\section{Introduction}

Gas sensors are devices which when exposed to certain gaseous species, are able to alter one or more of their physical properties. They have numerous applications, ranging from biomedicine to automobile industry. Recently, gas sensors attract tremendous interest due to increasing demand of sensitive, selective, fast response, stable, low cost sensors for environmental monitoring. Last decade, different techniques and various sensing materials have been developed, each improving the limitations of the previous. Typically, most of these sensing elements operate at elevated temperatures, which cause high power consumptions not appropriate for wireless application. However, since the discovery of carbon nanotubes (CNTs) in 1991, CNTs have been the focus of intensive research due to their superior characteristics such as chemical, thermal, and mechanical stability, semiconductive properties and functionalization capability $[1-3]$. These properties make them favorable candidates for active building elements in gas sensors [4-6], exploiting their sensing nature even at room temperatures $[7,8]$. The potential of CNTs as sensing element is based not only on these extraordinary properties, but also on their hollow structure and high surface-to-volume ratio $(\mathrm{A} / \mathrm{V})[9-11]$. The high $\mathrm{A} / \mathrm{V}$ ratio leads to an increase of the surface area of the reinforcing element, thus resulting in an increase of the area where stress transfer between the nanotube and polymer matrix oc-

*corresponding author; e-mail: anita.grozdanov@yahoo.com curs (increased absorptive capacity). Interaction with gas molecules affects the electrical properties of CNTs at room temperature, and they also display high response and good reversibility [12]. The overall performance of a CNT-polymer gas sensor depends strongly on the CNTs dispersion in the polymer matrix, which on the other hand is dependent on the CNTs/polymer interactions [13-15]. Until now, many papers on chemical modification and obtaining stable CNTs dispersion have been published, which suggest generation of different functional groups (hydroxyl, carboxyl, carbonyl, amine, etc.) to CNTs [16-24] or employment of various anionic, cationic, and nonionic surfactants [25-29].

Ever since the synthesis of the first CNTs-based sensor for $\mathrm{NH}_{3}$ and $\mathrm{NO}_{2}$ [30], many research papers have been published summarizing their potential and development throughout the years. Quite a few of these authors call upon percolation theory in explaining the electrical changes of insulating polymer matrix in which CNTs are dispersed [31-34]. Incorporation of CNTs in a polymer matrix is found to reduce the percolation threshold to a very low filler volume, and amorphous poly(methyl methacrylate) PMMA has been proven an easy to process polymer which fulfills this prerequisite (avoiding potential complications related to the crystallization) $[35,36]$.

In this work, poly(methyl methacrylate)/MWCNTs nanocomposite films were prepared and studied in order to develop a nano gas sensor for the detection of organic vapors. MWCNTs were preferred in this application versus a single walled carbon nanotubes (SWCNTs) because of their length, stiffness and bigger resistance than SWCNTs, as well as to reduce the cost for real application. The performance of the sensors was evaluated by study- 
ing the changes of their electrical resistivity in presence of acetone and chloroform.

\section{Experimental}

As a filler in the composites, MWCNTs produced at our lab (by method of pyrolysis), were used (outer diameter $d=10 \div 40 \mathrm{~nm}$, purity $\approx 94 \%$ ) [37]. The PMMA/MWCNTs nanocomposite films were prepared by casting solution technique, with dichloromethane as solvent. Desired weight of MWCNTs was added to $100 \mathrm{ml}$ of chloroform in a flask and the suspension was ultra sonicated for $30 \mathrm{~min}$. Then, a solution of $20 \%$ by weight of the PMMA-polymer matrix in the same solvent was prepared. After the polymer was dissolved, two mixtures were blended and stirred at room temperature for $30 \mathrm{~min}$. The final solution was then poured into the Petri dish and the solvent was evaporated at room temperature.

Nanocomposite films containing $0.2,0.5$, and $1.0 \mathrm{wt} \%$ MWCNTs were prepared. The desired quantity of MWCNT was determined vs. the quantity of PMMA in the solution (20\% PMMA). A neat PMMA film was also prepared and used as a reference.

The structural properties of the obtained polymer/MWCNTs nano composite films were studied by differential scanning calorimetry (DSC), thermogravimetric analysis (TGA), the Fourier-transform infrared (FTIR), $\mathrm{X}$-ray analysis (WAX), and scanning electron microscopy (SEM).

DSC measurements were performed with DSC system (Mettler Star) under $\mathrm{N}_{2}$ atmosphere in the nonisothermal regime (heating rate $=10 \mathrm{~K} / \mathrm{min}$, cooling rate $=10 \mathrm{~K} / \mathrm{min}) . \quad 8-9 \mathrm{mg}$ of material was used for each specimen. TGA was performed in the range of 50 to $800{ }^{\circ} \mathrm{C}$ with heating rate of $20 \mathrm{~K} / \mathrm{min}$ (in $\mathrm{N}_{2}$ ) using a Perkin Elmer Pyris DIAMOND TGA/DTA system. FTIR spectroscopy was used to characterize the structure of the PMMA/MWCNTs nanocomposites. FTIR spectra were recorded with Perkin Elmer Paragon 500 analyzer, using 64 scans and a resolution of $2 \mathrm{~cm}^{-1}$. SEM microphotographs were recorded with FEI Quanta 200 scanning electron microscope using an acceleration voltage of $30 \mathrm{kV}$ and a secondary electron detector X-ray diffraction (WAX) spectra of PMMA and PMMA/MWCNTs nanocomposite films were recorded using PAN-analytical X'Pert Pro diffractometer using $\mathrm{Cu} K_{\alpha}$ radiation between 2 and $40^{\circ} 2 \theta$.

The changes in the nanocomposite resistance were followed after exposure of PMMA/MWCNTs nanocomposite films to different gases (chloroform and acetone). Electro resistance was followed by KEITHLEY 8009 instrument, with 200 applied voltage during $30 \mathrm{~s}$, in the range $-200 /+200 \mathrm{~V}$.

\section{Results and discussion}

The obtained TGA curves are shown in Fig. 1. TGA analysis has shown that MWCNTs improved the thermal stability of nanocomposites based on PMMA. $T_{d}$ was raised by five degrees (at $339^{\circ} \mathrm{C}$, sample PMMA/1.0\%
MWCNTs), as shown in Table I. The other characteristic thermal parameters such as the onset temperature $\left(T_{o}\right)$ and the glass transition temperature $\left(T_{g}\right)$ were determined from DSC curves and the results are shown in Table I. The obtained DSC curves are shown in Fig. 2.

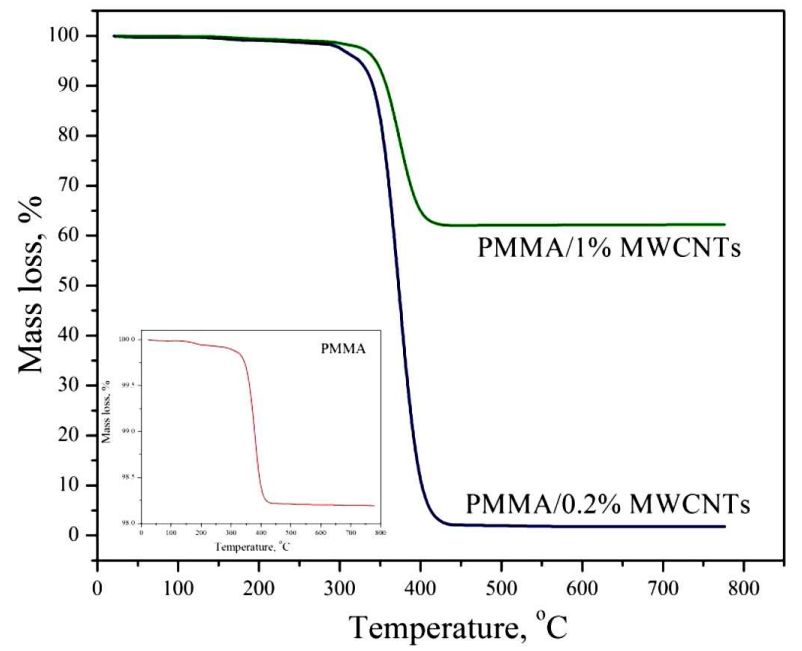

Fig. 1. TGA curves for PMMA and PMMA/MWCNTs nanocomposites.

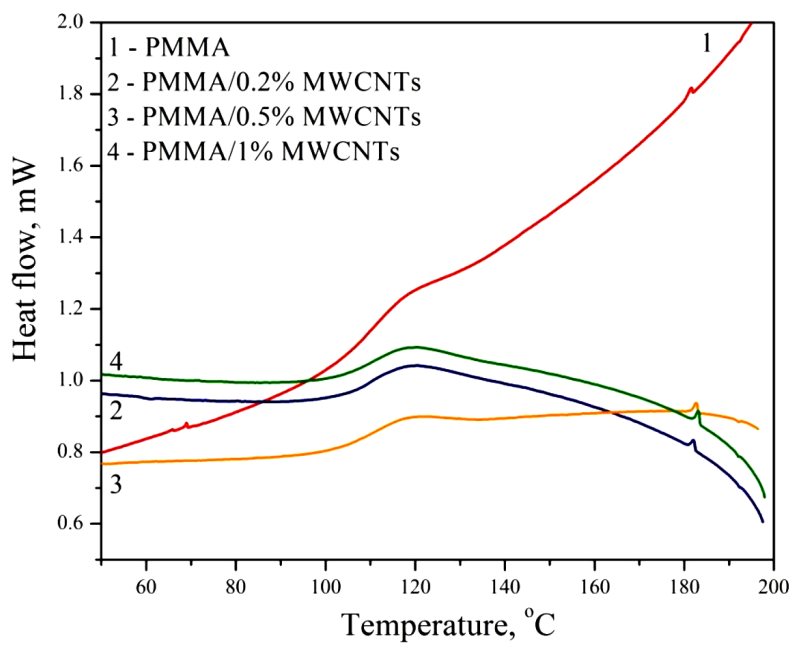

Fig. 2. DSC curves for PMMA and PMMA/MWCNTs nanocomposites.

TABLE I

Characteristic thermal data for PMMA $/ n$ MWCNTs nanocomposites.

\begin{tabular}{c|c|c|c|c}
\hline \hline \multirow{2}{*}{$n$} & $T_{d}$ & $T_{g}$ & $T_{o}$ & $\begin{array}{c}\Delta C_{p} \\
{\left[\mathrm{~J} \mathrm{~g}^{-1} \mathrm{~K}^{-1}\right]}\end{array}$ \\
\cline { 2 - 3 } & \multicolumn{3}{|c|}{$\left[{ }^{\circ} \mathrm{C}\right]$} & 0.288 \\
$0 \%$ & 334.2 & 116.8 & 110.9 & 0.233 \\
$0.2 \%$ & 338.2 & 114.8 & 110.5 & 0.295 \\
$1.0 \%$ & 338.8 & 113.9 & 109.5 & 0.296
\end{tabular}

It was found that as the MWCNTs content increased, both transition temperatures $\left(T_{0}\right.$ and $\left.T_{g}\right)$ were shifted to 
lower temperatures which indicate changes in the elastic behavior. The PMMA/MWCNTs nanocomposites have lower $T_{g}$ than pure PMMA.

Characteristic X-ray diffraction patterns for PMMA and PMMA/1.0\% MWCNTs nanocomposite are presented in Fig. 3. According to the literature, it is clearly observed that powder CNTs exhibit diffraction peaks at $2 \theta=26.6^{\circ}, 43.45^{\circ}$, and $54.7^{\circ}$ which correspond to (002), (101), and (004) phases, while broad bands diffraction peaks at $2 \theta=17^{\circ}$ and 32 correspond to PMMA [36]. In Fig. 3, it can be observed that PMMA curve (series 2 ), has shown broad diffraction peak at $2 \theta=14^{\circ}$ and sharp peak at $2 \theta=29^{\circ}$ which implies amorphous nature of PMMA [36]. In the case of PMMA, sharp peak which was registered at $2 \theta=29^{\circ}$ has been shifted to $2 \theta=39^{\circ}$ in the diffraction pattern of nanocomposite film due to the MWCNTs/polymer interactions. Decreased intensity of this peak in the WAX-curve of the nanocomposite film (series 1) suggests existence of compatible nanocomposite system, with compatible mixing of polymer and MWCNTs. Also, for nanocomposite films some shiftings of diffraction peaks towards lower values were registered which indicates changes in interlayer distance. This behavior indicated also that there was no covalent interactions between CNTs and PMMA [36]. In addition, this was proved for a homogeneous dispersion of CNTs in PMMA matrix. The obtained results are in agreement with the literature $[36,38]$.

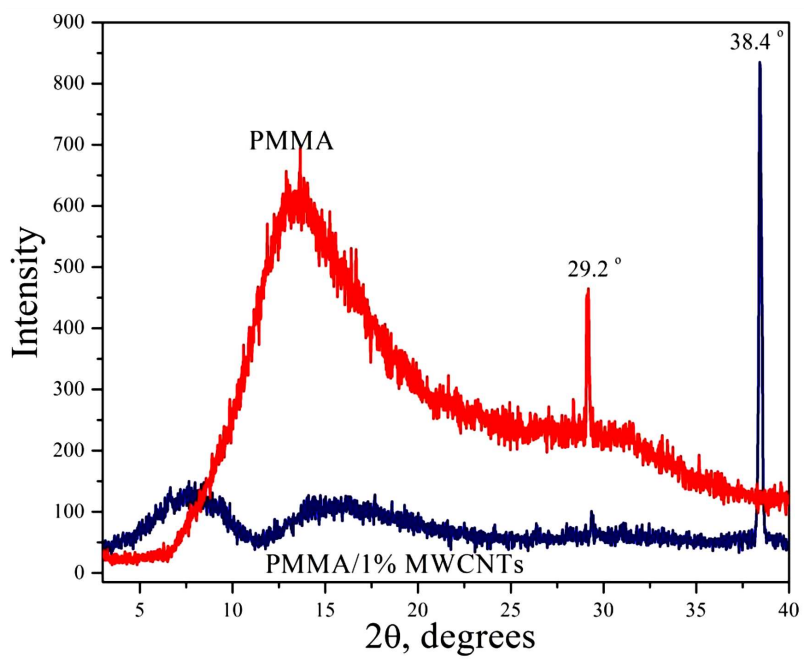

Fig. 3. WAX-analysis of PMMA/MWCNTs nanocomposite film.

To evaluate degree of MWCNTs dispersion within the polymer matrix, nanocomposites films have been observed by SEM. Characteristic morphology of PMMA based nanocomposites is shown in Fig. 4. SEM images clearly show that homogeneous dispersions of MWCNTs (well-dispersed bright dots) throughout PMMA are achieved at all CNTs contents, although at higher content of 1\% MWCNTs smaller aggregates are also observed.

FTIR spectroscopy was used extensively in the structural determination of molecules. FTIR spectra of

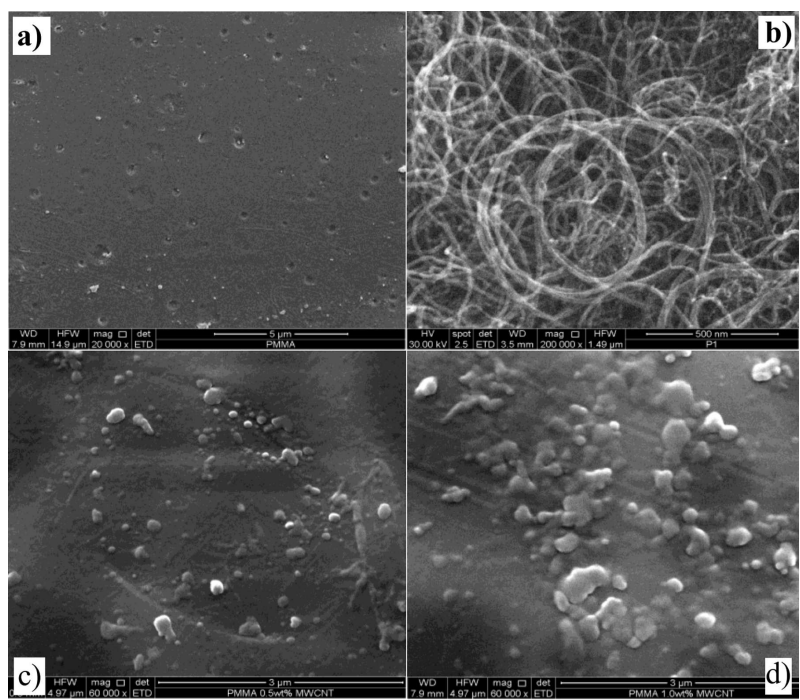

Fig. 4. SEM images of PMMA/MWCNTs nanocomposites: (a) pure PMMA, (b) MWCNTs, (c) PMMA $/ 0.5 \%$ MWCNTs, (d) PMMA $/ 1 \%$ MWCNTs.

PMMA and PMMA/MWCNTs nanocomposites are shown in Fig. 5. When comparing the FTIR spectra of PMMA and PMMA/MWCNTs composites, small peak shifts and only one significant change can be seen. Namely, the $\mathrm{C}-\mathrm{O}$ stretching bands observed at $1583 \mathrm{~cm}^{-1}$ and $1611 \mathrm{~cm}^{-1}$ in PMMA, remarkably decreased in PMMA/MWCNTs nanocomposites which indicates changes related to MWCNTs content in the polymer structure. Decrease of these peaks in the 1560$1600 \mathrm{~cm}^{-1}$ range indicates the changes in the CNTs structure upon carboxylation $[39,40]$. At the same time, the decrease of these peaks indicates presence of asymmetrical hexagonal carbon [41].

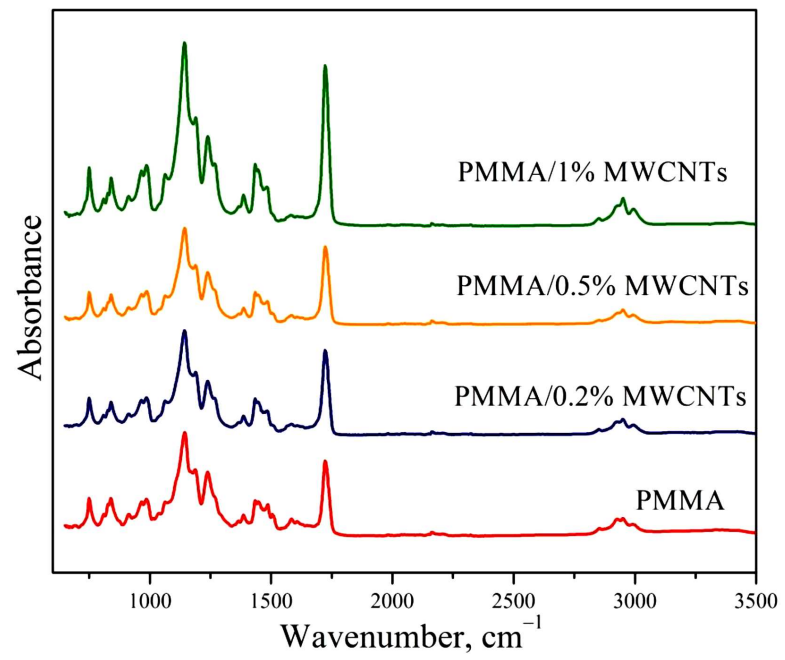

Fig. 5. FITR spectra of pure PMMA and PMMA/MWCNTs nanocomposites.

The response and changes in PMMA/MWCNTs nanocomposite electroresistivity due to gas exposure are 
presented in Table III, while the characteristic curves are shown in Fig. 6. $R_{o}$ is the initial electro resistivity, while $R$ is the value of electroresistivity after $30 \mathrm{~min}$ exposure to acetone and chloroform. Data showed that each agent impacts composites' electroresistivity and as such, is a good parameter for detecting and identifying gas presence.

\section{TABLE II}

Electroresistivity $[\Omega \mathrm{cm}]$ of $\mathrm{PMMA} / n \mathrm{MWCNTs}$ nanocomposites exposed for $30 \mathrm{~min}$ to acetone $\left(R_{a}\right)$ and chloroform $\left(R_{c}\right)$.

\begin{tabular}{c|c|c|c}
\hline \hline$n$ & $R_{0}$ & $R_{a}$ & $R_{c}$ \\
\hline $0 \%$ & $1.37 \times 10^{16}$ & $6.89 \times 10^{14}$ & $9.46 \times 10^{14}$ \\
$1 \%$ & $2.81 \times 10^{8}$ & $1.14 \times 10^{10}$ & $3.91 \times 10^{9}$ \\
$0.5 \%$ & $4.37 \times 10^{8}$ & $2.43 \times 10^{10}$ & $4.96 \times 10^{9}$ \\
$0.25 \%$ & $3.32 \times 10^{8}$ & $5.23 \times 10^{8}$ & $1.15 \times 10^{9}$
\end{tabular}

The obtained data presented in Table III show that integration of CNTs in PMMA resulted in formation of PMMA/CNTs nanocomposites with lower electroresistivity (i.e. higher conductivity) compared to that of pure PMMA matrix. Sensitivity of these PMMA/MWCNTs nanocomposites was calculated according to Eq. (1) [42]:

$$
S=\left|\frac{R-R_{o}}{R_{o}}\right|,
$$

where $R_{o}$ is electroresistivity of the composite before the exposure to acetone and chloroform, while $R$ is the maximal electroresistivity achieved after the exposure.

When varying the content of CNTs, $S$ has been calculated to be in $0.58-54.6$ range (30 min exposed to acetone) and $0.53-10.35$ (30 min exposed to chloroform). Based on these obtained values, it can be concluded that nanocomposites with incorporated MWCNTs showed more significant changes. Namely, it was found that electroresistivity decreases (in cases of both agents, acetone and chloroform), i.e. conductivity increases. These data indicate that by increasing the MWCNTs concentration in PMMA-based nanocomposites from 0.5 to $1.0 \%$ MWCNTs, remarkable increase of electroresistivity after exposure to both agents was registered.

Measurements after $30 \mathrm{~min}$ exposure to acetone and chloroform (Table III) show that PMMA/MWCNTs nanocomposites exposed to acetone exhibit more significant changes in electroresistivity than those exposed to chloroform, i.e. they display higher sensitivity to acetone. The obtained data have shown that when exposed to acetone, the studied PMMA/MWCNTs nanocomposites are good sensors for $-\mathrm{CO}$ detection. The obtained results are in agreement with experiments carried out by Abraham et al. on PMMA/MWCNTs nanocomposites [38].

According to Abraham et al., the electrical response of the PMMA/MWCNTs nanocomposite based gas sensors to organic solvents can be explained by the following mechanism [38]. Namely, inside CNTs/polymer composites conducting paths were formed due to quantum

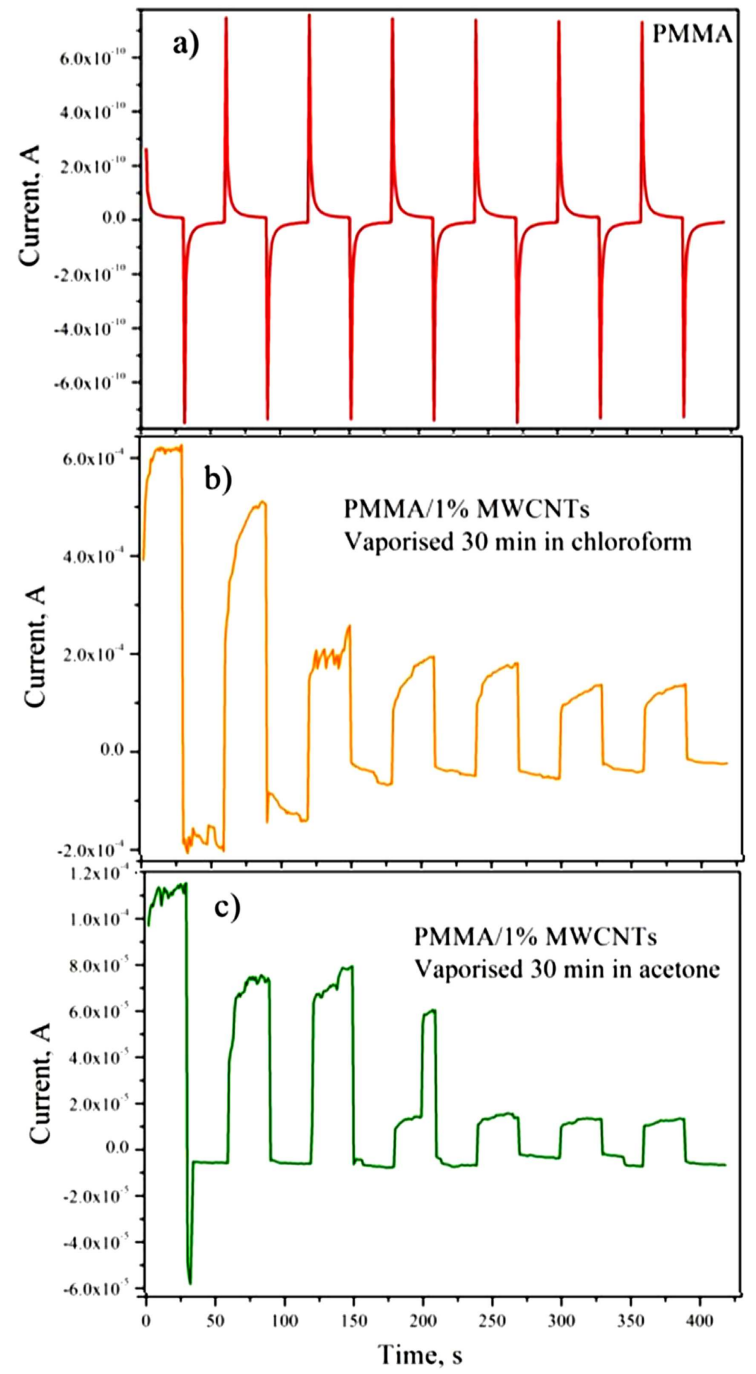

Fig. 6. Electric response to acetone and chloroform: (a) PMMA, (b) PMMA/1.0\%MWCNTs 30 min exposed to chloroform, (c) PMMA/1.0\%MWCNTs $30 \mathrm{~min}$ exposed to acetone.

mechanical tunneling effects, where the short distance between the conducting sticks enables electron hopping. Absorption of organic vapors results in swelling of the polymer matrix and increases distance between adjacent MWCNTs. This affects contact resistance and shifts it to higher values. The level of swelling and resulting electrical response depend on solubility of polymer in solvents. Additionally, the weak polymer-CNTs filler interactions and absence of crystallinity are both very crucial parameters which assist the achievement of high conductivity levels, since a closer approach of the conductive fillers in the developed network is allowed.

\section{Conclusions}

TGA/DTA analysis of PMMA/MWCNTs nanocomposites registered higher temperatures of degradation $\left(T_{d}\right)$. This confirmed that synthesized nanocompos- 
ites have better thermal stability. DSC thermograms showed that glass transition temperature $\left(T_{g}\right)$ was shifted to lower temperature as a result of increased MWCNTs content. This confirmed that changes in elastic behavior has been achieved. FTIR spectra of pure PMMA and PMMA/MWCNTs nanocomposites registered significant change (decrease) of C-O stretching band, which results from carbon oxidation. SEM showed that homogeneous dispersion of MWCNTs throughout PMMA was achieved, at all MWCNTs content. In sample PMMA/1.0\%MWCNTs smaller aggregates were observed. Response of PMMA/MWCNTs composites to vapors was measured after they were exposed $30 \mathrm{~min}$ to acetone and chloroform. It was found that electroresistivity decreases (in cases of both agents, acetone and chloroform), i.e. conductivity increases.

\section{References}

[1] S. Iijima, Nature 354, 56 (1991).

[2] S. Iijima, T. Ichihashi, Nature 363, 603 (1993).

[3] S. Niyogi, M.A. Hamon, H. Hu, B. Zhao, P. Bhowmik, R. Sen, M.E. Itkis, R.C. Haddon, Acc. Chem. Res. 35, 1105 (2002).

[4] P.M. Ajayan, O.Z. Zhou, Springer Topics in Applied Physics, Vol. 80, Ed. M.S. Dresselhaus, G. Dresselhaus, Ph. Avouris, Springer, Berlin 2001, p. 391.

[5] Y. Saito, K. Hamaguchi, S. Uemura, K. Uchida, Y. Tasaka, F. Ikazaki, M. Yumura, A. Kasuya, Y. Nishina, Jpn. J. Appl. Phys. A 67, (1998).

[6] L. Valentini, L. Lozzi, C. Cantalini, I. Armentano, J.M. Kenny, L. Ottaviano, S. Santucci, Thin Solid Films 436, 95 (2003).

[7] K.G. Ong, K. Zeng, C.A. Grimes, IEEE Sensors J. 2, 82 (2002).

[8] B. Philip, J.K. Abraham, A. Chandarsaker, V.K. Varadan, Smart Mater. Struct. 12, (2003).

[9] E.T. Thostenson, Z. Ren, T.-W. Chou, Compos. Sci. Technol. 61, 1899 (2001).

[10] E.T. Thostenson, C. Li, T.-W. Chou, Compos. Sci. Technol. 65, 491 (2005).

[11] S.C. Tjong, Exp. Polym. Lett. 4, 516 (2010).

[12] A.C. Dillon, K.M. Jones, T.A. Bekkedahl, C.H. Kiang, D.S. Bethune, M.J. Heben, Nature 386, (1977).

[13] D. Tasis, N. Tagmatarchis, A. Bianco, M. Prato, Chem. Rev. 106, 1105 (2006).

[14] F. Aviles, J.V. Cauich-Rodriguez, J.A. RodriguezGonzalez, A. May-Pat, Exp. Polym. Lett. 5, 766 (2011).

[15] J. Chen, M.A. Hamon, H. Hu, Y. Chen, A.M. Rao, P.C. Eklund, R.C. Haddon, Science 282, 95 (1998).

[16] M.S.P. Shaffer, A.H. Windle, Adv. Mater. 11, 937 (1999).

[17] X.L. Xie, Y.W. Mai, X.P. Zhou, Mater. Sci. Eng. R Rep. R49, 89 (2005).

[18] M.S.P. Shaffer, X. Fan, A.H. Windle, Carbon 36, 1603 (1998)
[19] J. Chen, A.M. Rao, S. Lyuksyutov, M.E. Itkis, M.A. Hamon, H. Hu, R. Cohn, P.C. Eklund, D.T. Colbert, R.E. Smalley, R.C. Haddon, J. Phys. Chem. B 105, 2525 (2001).

[20] J. Liu, A.G. Rinzler, H. Dai, J.H. Hafner, R.K. Bradley, P.J. Boul, A. Lu, T. Iverson, K. Shelimov, C.B. Huffman, F. Rodriguez-Macias, Y.S. Shon, T.R. Lee, D.T. Colbert, R.E. Smalley, Science 280, 1253 (1998).

[21] C. Gao, Y.Z. Jin, H. Kong, R.L.D. Whitby, S.F.A. Acquah, G.Y. Chen, H. Qian, A. Hartschuh, S.R.P. Silva, S. Henley, P. Fearon, H.W. Kroto, D.R.M. Walton, J. Phys. Chem. B 109, 11925 (2005).

[22] K. Kamaras, M.E. Itkis, H. Hu, B. Zhao, R.C. Haddon, Science 301, 1501 (2003).

[23] V. Georgakilas, N. Tagmatarchis, D. Pantarotto, A. Bianco, J.P. Briand, M. Prato, Chem. Commun. 2002, 3050 (2002).

[24] D. Tasis, N. Tagmatarchis, V. Georgakilas, M. Prato, Chemistry 9, 4000 (2003).

[25] O. Matarredona, H. Rhoads, Z. Li, J.H. Harwell, L. Balzano, D.E. Resasco, J. Phys. Chem. B 107, 13357 (2003).

[26] K. Yurekli, C.A. Mitchell, R. Krishnamoorti, J. Am. Chem. Soc. 126, 9902 (2004).

[27] N. Grossiord, O. Regev, J. Loos, J. Meuldijk, C.E. Koning, Anal. Chem. A 77, 5135 (2005).

[28] D. Li, H. Wang, J. Zhu, X. Wang, L. Lu, X. Yang, J. Mater. Sci. Lett. 22, 253 (2003).

[29] Z.H. Wang, G.A. Luo, S.F. Xiao, Proc. IEEE Sensors 2, 941 (2003).

[30] J. Kong, N.R. Franklin, C.W. Zhou, M.G. Chapline, S. Peng, K.J. Cho, H. Dai, Science 287, 622 (2000).

[31] L. Valentini, J. Biagiott, J.M. Kenny, S. Santucci, Compos. Sci. Technol. 63, 1149 (2003).

[32] B. Safadi, R. Andrews, E.A. Grulke, J. Appl. Polym. Sci. 84, 2660 (2002).

[33] H.W. Goh, S.H. Goh, G.Q. Xu, K.P. Pramoda, W.D. Zhang, Chem. Phys. Lett. 373, 277 (2003).

[34] A. Allaoui, S. Baia, H.M. Cheng, J.B. Baia, Compos. Sci. Technol. 62, 1993 (2002).

[35] B. Philip, J.K. Abraham, A. Chandrasekhar, V.K. Varadan, Smart Mater. Struct. 12, 935 (2003).

[36] E. Logakis, C. Pandis, P. Pissis, J. Pionteck, P. Potschke, Compos. Sci. Technol. 71, 854 (2011).

[37] A. Tomova, G. Gentile, A. Grozdanov, M.E. Errico, P. Paunovic, M. Avella, A.T. Dimitrov, Acta Phys. Pol. A 129, 405 (2016).

[38] J.K. Abraham, B. Philip, A. Witchurch, V.K. Varadan, C.C. Reddy, Smart Mater. Struct. 13, 1045 (2004).

[39] S. Chen, W. Shen, G. Wu, D. Chen, M. Jiang, Chem. Phys. Lett. 402, 302 (2005).

[40] S.Y. Lee, S.J. Park, Bull. Korean Chem. Soc. 31 , 1596 (2010).

[41] R. Yudijanti, H. Onggo, Sudirman, Y. Saito, T. Iwata, J. Azuma, Open Mater. Sci. J. 5, 242 (2011).

[42] J. Chen, N. Tsubokova, Polym. Adv. Technol. 11, $101(2000)$. 